Pesq. Vet. Bras. 22(1):7-12, jan./mar. 2002

\title{
Imunofluorescência utilizando isolados brasileiros no diagnóstico sorológico de infecção por lentivírus em caprinos ${ }^{1}$
}

\author{
Dilmara Reischak ${ }^{2 *}$, Ana Paula Ravazzolo ${ }^{3}$ e Valéria Moojen ${ }^{2}$
}

\begin{abstract}
Reischak D., Ravazzolo A.P. \& Moojen V. 2002. [Immunofluorescence using Brazilian isolates for serological diagnosis of lentivirus infection in goats.] Imunofluorescência utilizando isolados brasileiros no diagnóstico sorológico de infecção por lentivírus em caprinos. Pesquisa Veterinária Brasileira 22(1):7-12. Faculdade de Veterinária, Universidade Federal do Rio Grande do Sul, Av. Bento Gonçalves 9090, Porto Alegre, RS 91540-000, Brazil. E-mail: dilchak@hotmail.com

Small ruminant lentiviruses (SRLV) are distributed worldwide and cause persistent infections in sheep and goats. The purpose of this work was to develop an indirect immunofluorescent antibody (IFA) test using Brazilian SRLV isolates for serological diagnosis of infection in goats. The IFA test was compared in its sensitivity and specificity to the AGID test in which Maedi-Visna WLC-1 strain was used as antigen. Ovine synovial secondary cell cultures infected with two goat SRLV isolates (CAEV UFRGS/Br-2 and CAEV UFRGS/Br-5) were used for the IFA. Goat serum samples $(n=239)$ were tested by the two tests. The AGID test detected antibodies in $129(53.9 \%)$ serum samples. A higher number of animals was considered positive for the IFA. However, different results were obtained depending on the isolate used for the antigen preparation. When CAEV UFRGS/Br-2 was used as antigen, $216(90.3 \%)$ serum samples tested positive, against 213 (89.1\%) with CAEV UFRGS/Br-5. There was no significant statistical difference between the antigens prepared with these two isolates. The IFA had sensitivity of $94.6 \%$ and $96.9 \%$, and specificity of $14.5 \%$ and $20 \%$, when CAEV UFRGS/Br- 2 and CAEV UFRGS/Br-5 were used as antigens, respectively. These results demonstrate that the IFA with antigens prepared with Brazilian SRLV isolates may play an important a role as a complementary serological test for the diagnosis of infections by these agents.
\end{abstract}

INDEX TERMS: Small ruminant lentiviruses, Brazilian isolates, diagnosis, indirect immunofluorescence, immunodiffusion, goats.

RESUMO.- Os lentivírus de pequenos ruminantes (SRLV) têm distribuição mundial e causam infeç̧ões persistentes em ovinos e caprinos. $\mathrm{O}$ objetivo deste trabalho foi desenvolver um teste de imunofluorescência indireta (IFA), utilizando isolados brasileiros de SRLV, para o diagnóstico sorológico de in-

\footnotetext{
${ }^{1}$ Aceito em 18 de dezembro de 2001.

Parte da Dissertação de Mestrado da primeira autora junto ao Programa de Pós-Graduação em Ciências Veterinárias (PPGCV) da Faculdade de Veterinária (FAVET) da Universidade Federal do Rio Grande do Sul (UFRGS). Trabalho realizado com suporte do CNPq, PPGCV e da Finep (PRONEX em Virologia Veterinária-215/96).

${ }^{2}$ FAVET-UFRGS. *Autora para correspondência: Faculdade de Veterinária da UFRGS, Av. Bento Gonçalves 9090, Porto Alegre, RS 91540-000. Fax: (51) 33167305. E-mail: dilchak@hotmail.com

${ }^{3}$ FAVET e Centro de Biotecnologia, UFRGS.
}

feç̧ão por estes agentes em caprinos. A técnica de IFA foi comparada, quanto à sensibilidade e à especificidade, ao teste de AGID com antígeno do vírus Maedi-Visna WLC-1. Cultivos celulares secundários de membrana sinovial ovina infectadas com dois isolados de SRLV de origem caprina (CAEV Br/UFRGS-2 e CAEV Br/UFRGS-5) foram utilizados para o teste de IFA. Duzentas e trinta e nove amostras de soro caprino foram submetidas aos dois testes. O teste de AGID detectou 129 (53.9\%) amostras de soro caprino com anticorpos para SRLV. O teste de IFA detectou mais amostras reagentes, sendo que resultados diferentes foram observados de acordo com o isolado de SRLV empregado. Quando o isolado CAEV Br/UFRGS-2 foi utilizado como antígeno, 216 (90.3\%) amostras de soro caprino foram reagentes, enquanto que $o$ isolado CAEV Br/UFRGS-5 detectou 213 (89.1\%) amostras de soro positivas. Não houve diferença estatisticamente significativa 
entre esses dois isolados. $\mathrm{O}$ teste de IFA desenvolvido teve sensibilidade de $94.6 \%$ e $96.9 \%$ e especificidade $14.5 \%$ e $20 \%$, quando os isolados CAEV Br/UFRGS-2 e CAEV Br/UFRGS-5 foram usados como antígeno, respectivamente. $O$ aprimoramento da técnica, assim como sua comparação com um teste mais sensível, ainda se fazem necessários. No entanto, os resultados demonstraram que a técnica de IFA, utilizando isolados brasileiros de SRLV como antígeno, apresenta potencial como um teste alternativo e complementar para o diagnóstico sorológico de infecção por estes agentes.

TERMOS DE INDEXAÇÃO: Lentivírus de pequenos ruminantes, isolados brasileiros, diagnóstico, imunofluorescência indireta, imunodifusão em gel de ágar, caprinos.

\section{INTRODUÇÃO}

Os lentivírus de pequenos ruminantes ("small ruminants lentiviruses" - SRLV), vírus da artrite-encefalite caprina (CAEV) e vírus Maedi-Visna dos ovinos (MVV), pertencem à família Retroviridae sendo estreitamente relacionados biológica, fenotípica e antigenicamente (Pasick 1998). Os caprinos jovens infectados desenvolvem, geralmente, um quadro de leucoencefalomielite, enquanto os adultos apresentam a síndrome da artrite-encefalite caprina (CAE) caracterizada por artrite, pneumonia e mamite (Perrin 1989).

Os SRLV encontram-se mundialmente difundidos, sendo mais prevalentes em países com sistemas intensivos de produção caprina e ovina (Rowe \& East 1997, Concha-Bermejillo 1997). No Brasil, a infecção por SRLV em caprinos tem sido relatada em diversos rebanhos, sendo primeiramente detectada no Rio Grande do Sul em 1986 (Moojen et al. 1986). Entretanto, caprinos soropositivos já estavam presentes no país (Rio de Janeiro) pelo menos desde de 1982, conforme estudos de Cunha \& Nascimento em 1995. A presença de animais sorologicamente positivos para CAEV foi também relatada em diferentes Estados brasileiros, como Bahia (Fiterman 1988, Assis \& Gouveia 1994), São Paulo (Garcia et al. 1992), Pernambuco (Saraiva Neto et al. 1995, Castro 1998), Minas Gerais (Assis \& Gouveia 1994, Dezan 1996), Ceará (Assis \& Gouveia 1994, Alves \& Pinheiro 1997, Melo \& Franke 1997), Maranhão (Alves \& Pinheiro 1997), Paraíba (Souza \& Alves 1999) e Santa Catarina (Sell et al. submetido à publicação). $O$ primeiro isolamento de CAEV no Brasil foi feito no Rio Grande do Sul, a partir da membrana sinovial de um caprino clínica e sorologicamente positivo à infecção por SRLV por Hötzel et al. (1993).

O sucesso em controlar a difusão da infecção por SRLV depende da deteç̧ão precoce e da remoção dos animais infectados (Rowe $\&$ East 1997). Devido à confiabilidade, praticidade na coleta de amostras e baixo custo, a detecção de anticorpos é o método mais empregado para diagnosticar a infecção (Knowles 1997). Os testes sorológicos rotineiramente utilizados são a imunodifusão em gel de ágar (AGID) (Cutlip et al. 1977) e o ELISA (Archambault et al. 1988, Rimstad et al. 1994). No entanto, estes testes podem ter sua sensibilidade afetada por algumas das características das infecções por lentívirus, o que têm implicação direta no sucesso ou não dos programas de controle (Hanson et al. 1996). Em virtude da grande variabilidade genômica e antigênica dos isolados de SRLV (Rosati et al. 1995, Leroux et al. 1997, Marchesin et al. 1998, Zanoni 1998, Ravazzolo et al. 2001) faz-se necessário que sejam desenvolvidas técnicas sensíveis e específicas para o diagnóstico. Dentro destes preceitos, o uso de antígenos produzidos com isolados autóctones seria indicado, o que reduziria o número de resultados falso-negativos.

A técnica de imunofluorescência indireta (IFA) tem sido empregada para o diagnóstico sorológico de infecção pelo vírus da imunodeficiência humana (HIV) desde a primeira caracterização deste agente (Gallo 1986), sendo utilizada, rotineiramente, em laboratórios de referência no Brasil (Daher et al. 1999). Apesar de sua vasta utilização na pesquisa de anticorpos para diversos agentes virais, são escassos os registros de emprego desta técnica em estudos com lentivírus animais (Dawson et al. 1982, Miyazawa et al. 1998, Cavirani et al. 1998). O objetivo do presente trabalho foi desenvolver uma técnica de IFA, empregando isolados brasileiros de SRLV de origem caprina, para o diagnóstico de infecção por estes agentes em caprinos e compará-la, quanto à sensibilidade e à especificidade, ao teste de AGID que emprega como antígeno $o$ isolado americano de origem ovina MVV WLC-1.

\section{MATERIAL E MÉTODOS}

\section{Cultivo celular}

Cultivos celulares primários foram estabelecidos a partir de explantes de membrana sinovial ovina (MSO) de animais negativos aos testes de imunodifusão em gel de ágar (AGID) e reação em cadeia da polimerase (PCR), como descrito por Crawford et al. (1980). Os cultivos secundários então obtidos, denominados de MSO-50, foram utilizados para inoculação e titulação dos isolados de lentivírus de pequenos ruminantes e confecção das lâminas para o teste de imunofluorescência indireta (IFA). Os cultivos celulares foram mantidos à temperatura de $37^{\circ} \mathrm{C} \mathrm{em}$ meio essencial mínimo (MEM) de Eagle com sais de Earle, acrescido de soro fetal bovino (SFB) em concentrações de 2 a $10 \%$ para manutenção e crescimento, respectivamente.

\section{Isolados de lentivírus de pequenos ruminantes}

Foram utilizados neste trabalho dois isolados brasileiros de lentivírus de pequenos ruminantes (SRLV) de origem caprina anteriormente obtidos a partir de animais naturalmente infectados e com sinais clínicos de infecção pelo vírus (Laboratório de Virologia Clínica da Faculdade de Veterinária da UFRGS). Esses isolados foram identificados como CAEV Br/UFRGS-2 e CAEV Br/UFRGS-5, anteriormente denominados de CAEV 767 e CAEV 047, respectivamente (Moojen 1996).

\section{Amostras de soro}

Duzentas e trinta e nove amostras de soro caprino obtidas de animais pertencentes a propriedades dos Estados do Ceará, Goiás, Minas Gerais, Mato Grosso do Sul, Rio Grande do Sul e Santa Catarina foram utilizadas para pesquisa de anticorpos para SRLV através das técnicas de AGID e IFA. Todas as amostras pertenciam ao estoque do Laboratório de Virologia Clínica da FAVET-UFRGS.

\section{Imunodifusão em gel de ágar}

$O$ teste de AGID foi realizado como descrito por Cutlip et al. (1977). Os reagentes comerciais empregados de acordo com a 
recomendação do fabricante foram produzidos pelo "Veterinary Laboratories Agency" (New Haw, Addlestone, Reino Unido) e consistiam de antígeno originado do isolado MVV WLC-1 e de padrões de soro controle positivos anti-p28 e anti-gp135 de origem caprina e ovina, respectivamente.

\section{Preparação das lâminas para imunofluorescência indireta}

As lâminas utilizadas para o teste de imunofluorescência indireta (IFA) foram produzidas a partir dos cultivos celulares MSO-50 inoculados com sobrenadantes de cultivos celulares infectados com os isolados CAEV Br/UFRGS-2 e CAEV Br/UFRGS-5, em multiplicidade de infecção $(\mathrm{MOI})^{3}{ }^{1}$. Os cultivos foram tripsinizados ao apresentarem pelo menos $30 \%$ do tapete celular com efeito citopático (CPE). Após centrifugação durante $10 \mathrm{~min}$ a $1000 \mathrm{x} \mathrm{g}$, o sobrenadante foi desprezado e as células foram ressuspendidas em PBS pH 7,4 a 4$8^{\circ} \mathrm{C}$ e novamente centrifugadas. Este procedimento de lavagem foi repetido três vezes. Após as lavagens, o sedimento celular foi ressuspendido em $\mathrm{PBS} \mathrm{pH} 7,4$ a $4-8^{\circ} \mathrm{C}$ a fim de se obter uma concentração de $1 \times 10^{6}$ células viáveis $/ \mathrm{ml}$. As lâminas para imunofluorescência (Knittel Gläser) continham dez orifícios com 7 $\mathrm{mm}$ de diâmetro cada, sendo que em cada orifício foram colocados $20 \mathrm{ml}$ da suspensão celular (= 20.000 células). As lâminas foram incubadas $30 \mathrm{~min}$ a $37^{\circ} \mathrm{C}$ para fixação das células as mesmas, sendo então fixadas por imersão em acetona a $4^{\circ} \mathrm{C}$ por $10 \mathrm{~min}$ e armazenadas $\mathrm{a}-20^{\circ} \mathrm{C}$.

\section{Realização da técnica de IFA}

A técnica de IFA foi realizada basicamente segundo Zapiola et al. (1995). As amostras de soro caprino foram diluídas a 1:10 em PBS $\mathrm{pH} 7,4$ e a antigamaglobulina caprina conjugada com isotiocianato de fluoresceína (Sigma, F-7367) foi diluída a 1:500. Sobre cada orifício da lâmina foram colocados $20 \mathrm{ml}$ de uma amostra de soro caprino. Em cada lâmina foram colocados também um controle positivo e um controle negativo (amostra de soro caprino positivo/negativo para infecção por SRLV por AGID e/ou por PCR a partir de leucócitos do sangue periférico). As lâminas foram incubadas em câmara úmida por $60 \mathrm{~min}$ a $37^{\circ} \mathrm{C}$ e submetidas a duas lavagens de 5 min cada em PBS pH 9,0, sob agitação, à temperatura ambiente (aproximadamente $25^{\circ} \mathrm{C}$ ). $\mathrm{O}$ excesso de $\mathrm{PBS}$ foi retirado com papel absorvente e foram então distribuídos $15 \mathrm{ml}$ do conjugado anti-IgG caprino sobre cada orifício. Após incubação de $30 \mathrm{~min}$ a $37^{\circ} \mathrm{C}$, as lâminas foram submetidas a duas lavagens, como anteriormente descrito. Na montagem das lâminas foi utilizado PBS-glicerol 50\% pH 9,0 e lamínulas para visualização ao microscópio de epifluorescência (Standard, Carl Zeiss). A leitura das lâminas foi realizada em aumento de 400X, utilizando-se filtros de excitação para comprimento de onda entre 450 a $490 \mathrm{~nm}$. A reação foi considerada positiva quando as células apresentaram fluorescência de membrana e/ou citoplasmática.

\section{Validação do teste}

Foi realizado um estudo comparativo dos resultados obtidos nos testes de AGID e IFA, tomando o primeiro como teste padrão. Foram avaliados os parâmetros de sensibilidade (Se), especificidade ( $\mathrm{Sp}$ ), valor preditivo positivo (VPP), valor preditivo negativo (VPN) e eficiência (E). Estes parâmetros foram calculados segundo Fletcher et al. (1996) e Ceballos et al. (1998), de acordo com o disposto no Quadro 1.

\section{Análise estatística}

Foi utilizado o teste de McNemar (Remington \& Schork 1970) para comparar os resultados dos testes de AGID e IFA e verificar
Quadro 1. Esquema de comparação entre os testes de imunodifusão em gel de ágar (AGID) e imunofluorescência indireta (IFA)

\begin{tabular}{ccc}
\hline \multirow{2}{*}{ IFA } & \multicolumn{2}{c}{ AGID } \\
\cline { 2 - 3 } & Positivos & Negativos \\
\hline Positivos & Verdadeiros-positivos (VP) & Falsos-positivos (FP) \\
Negativos & Falsos-negativos (FN) & Verdadeiros-negativos (VN)
\end{tabular}

possíveis diferenças entre os resultados obtidos com os diferentes isolados de SRLV empregados nesta última técnica.

\section{RESULTADOS}

\section{Imunodifusão em gel de ágar}

A visualização de linhas de precipitação indicou a presença de anticorpos específicos para SRLV, sendo que as amostras foram classificadas como positivas (formação de linha de identidade entre o soro controle positivo e a amostra em teste em relação ao antígeno), negativas (não formação de linha de identidade) ou suspeitas (leitura inconclusiva).

Das 239 amostras de soro caprino submetidas ao teste de AGID, 70 (29.3\%) foram positivas, 110 (46\%) negativas e 59 (24.7\%) foram consideradas suspeitas (Fig. 1).

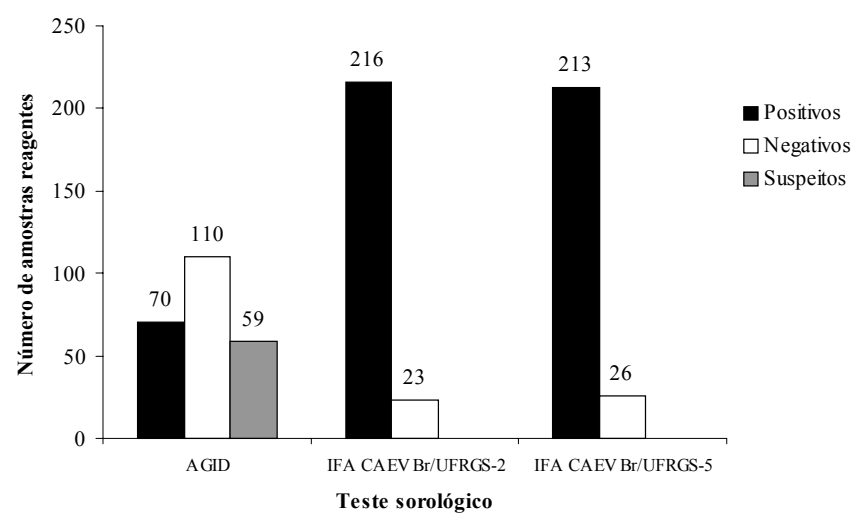

Fig. 1. Resultados obtidos nos testes de imunodifusão em gel de ágar (AGID) e imunofluorescência indireta (IFA) utilizando dois isolados brasileiros de lentivírus de pequenos ruminantes (CAEV $\mathrm{Br} /$ UFRGS-2 e CAEV Br/UFRGS-5) para pesquisa de anticorpos em 239 amostras de soro caprino.

\section{Imunofluorescência indireta}

Os resultados obtidos no teste de IFA são apresentados na Figura 1. No teste de IFA com antígeno CAEV Br/UFRGS-2 (IFA CAEV Br/UFRGS-2) 216 amostras de soro (90.4\%) tiveram resultado positivo, enquanto $213(89.1 \%)$ tiveram este mesmo resultado quando o isolado CAEV Br/UFRGS-5 (IFA CAEV Br/UFRGS-5) foi utilizado como antígeno.

\section{Validação do teste}

Os resultados da comparação entre os testes de AGID e IFA utilizados neste trabalho estão representados no Quadro 2. Os valores estimados de Se, Sp, VPP, VPN e E para o teste de IFA em relação ao teste padrão de AGID são apresentados no Quadro 3. 
Quadro 2. Comparação dos resultados obtidos nos testes de imunodifusão em gel de ágar (AGID) e imunofluorescência indireta (IFA) para 239 amostras de soro caprino

\begin{tabular}{|c|c|c|c|c|}
\hline \multirow[t]{2}{*}{ IFA } & \multicolumn{4}{|c|}{ AGID } \\
\hline & & Positivo & Negativo & Total IFA \\
\hline \multirow[t]{2}{*}{ CAEV Br/UFRGS-2a } & Positivo & 122 & 94 & $216(90,4 \%)$ \\
\hline & Negativo & 7 & 16 & $23(9,6 \%)$ \\
\hline \multirow[t]{2}{*}{ CAEV Br/UFRGS- $5^{\mathrm{a}}$} & Positivo & 125 & 88 & $213(89,1 \%)$ \\
\hline & Negativo & 4 & 22 & $26(10,9 \%)$ \\
\hline Total AGID & & $129(54 \%)$ & $110(46 \%)$ & 239 (100\%) \\
\hline
\end{tabular}

Quadro 3. Valores estimados de sensibilidade (Se), especificidade (Sp), valor preditivo positivo (VPP), valor preditivo negativo (VPN) e eficiência (E) para o teste de imunofluorescência indireta (IFA) em relação ao teste padrão de imunodifusão em gel de ágar (AGID)

\begin{tabular}{cccccc}
\hline Teste & Se & Sp & VPP & VPN & E \\
\hline IFA CAEV Br/UFRGS-2 & 94,6 & 14,5 & 56,5 & 69,6 & 57,7 \\
IFA CAEV Br/UFRGS-5 & 96,9 & 20 & 58,7 & 84,6 & 61,5
\end{tabular}

\section{Análise estatística}

Para que os resultados obtidos nos testes de AGID e IFA pudessem ser comparados estatisticamente, as amostras de soro caprino consideradas suspeitas no teste de AGID foram reagrupadas como positivas.

O teste de IFA desenvolvido com os dois isolados de SRLV para diagnóstico de infeç̧ão em caprinos foi capaz de detectar mais animais positivos do que o teste de AGID, sendo a diferença estatisticamente significativa $(p<0,001)$. Os resultados obtidos nos testes de IFA CAEV Br/UFRGS-2 e IFA CAEV Br/UFRGS-5 não apresentaram diferença estatisticamente significativa entre si.

\section{DISCUSSÃO}

O teste de imunofluorescência indireta (IFA) desenvolvido neste trabalho detectou um maior número de animais positivos quando comparado ao teste padrão de imunodifusão em gel de ágar (AGID). Os diferentes resultados obtidos à IFA podem ser decorrentes de reações a uma variedade de antígenos que não são detectáveis ao teste de AGID. Resultados similares foram obtidos quando a IFA foi comparada ao Western blot para diagnóstico sorológico de infecção pelo HIV e pelo vírus da imunodeficiência bovina (BIV). Mahony et al. (1989) verificaram que amostras de soro humano que apresentavam anticorpos apenas para a gp41 do HIV no teste de Western blot, sendo seu resultado considerado como indeterminado, foram positivas por IFA. Da mesma forma, Cavirani et al. (1998) em estudo de soroprevalência para infecção pelo BIV na Itália, observaram que das 85 amostras de soro bovino positivas à IFA, 81 (95.3\%) apresentaram anticorpos para p26 ao Western blot, enquanto quatro (4.7\%) reagiram com outras proteínas virais. Amostras de soro coletadas de animais em diferentes fases de infecção e a exis- tência de isolados antigenicamente distintos também podem explicar os resultados discordantes nos dois testes (Cavirani et al. 1998). A reação antigênica cruzada entre isolados de CAEV e MVV envolve todas as principais proteínas e glicoproteínas associadas ao virion (Gogolewski et al. 1985). Em virtude dessa reatividade cruzada entre proteínas estruturais de lentivírus de pequenos ruminantes (SRLV), antígenos de MVV, que alcançam altos títulos in vitro, podem ser utilizados para detectar anticorpos específicos para SRLV tanto em ovinos como em caprinos. Com base nesta similaridade antigênica e por estar disponível no mercado internacional, o antígeno empregado neste trabalho foi de origem ovina, contendo os antígenos gp135 e p28 do isolado WLC-1 e os respectivos padrões de soro, o que confere maior sensibilidade ao teste de AGID. Se um antígeno de origem caprina tivesse sido utilizado neste trabalho, presume-se que um maior número de caprinos seria diagnosticado como positivo, uma vez que a sensibilidade do teste de AGID pode ser incrementada pelo uso de antígenos homólogos (Knowles et al. 1994). Fatores como soroconversão tardia, variação no título de anticorpos para SRLV ao longo da vida do animal (Hanson et al. 1996) e heterogeneidade genômica dos isolados também podem influenciar o resultado dos testes sorológicos e subestimar o número de animais infectados. Por estes motivos, testes complementares, como a IFA, podem ser desenvolvidos e empregados, a exemplo do que ocorre em trabalhos de diagnóstico de infecção pelo HIV, onde a IFA é utilizada como teste confirmatório para amostras de soro de indivíduos classificados como reagentes ou indeterminados por teste imunoenzimático.

Apesar da especificidade estimada para o teste de IFA ter sido baixa neste estudo, alguns fatores devem ser considerados para a análise dos resultados. Segundo Fletcher et al. (1996), quando dois testes diagnósticos são comparados é preciso escolher como padrão de validade um teste que seja considerado o melhor disponível para aquele caso. No entanto, segundo o mesmo autor, na prática nenhum teste é perfeito e, sendo assim, o teste utilizado como padrão pode ser menos sensível ou menos específico que o teste que está sendo desenvolvido.

O AGID foi utilizado neste trabalho como teste padrão em virtude de sua utilização em programas de controle e erradicação da infecção por SRLV e por ser o teste recomendado pela Organização Internacional de Epizootias para o diagnóstico sorológico de infecção por SRLV no caso de comércio internacional de pequenos ruminantes (OIE 1996, Knowles 1997). Apesar de específico, o teste de AGID mostrou-se menos sensível do que vários testes de ELISA desenvolvidos para diagnóstico de infecção por SRLV (Houwers \& Schaake 1987, Rosati et al. 1994, Celer Jr et al. 1998). Esta baixa sensibilidade pode ser explicada pelos mecanismos de interação antígenoanticorpo. Enquanto os testes imunoenzimáticos requerem a interação de apenas um epitopo por anticorpo para obter um resultado positivo, o teste de AGID requer várias destas interações (Celer Jr et al. 1998). Além disto, alterações antigênicas nas proteínas e glicoproteínas contidas no antígeno também podem influenciar a sensibilidade do teste, como já 
discutido. Verificou-se neste estudo que a IFA detectou mais animais soropositivos do que o teste de AGID, mas estes indivíduos identificados adicionalmente pela IFA foram considerados falsos-positivos em relação ao AGID, segundo os critérios de validação utilizados, o que colaborou significativamente para a baixa especificidade estimada para o teste de IFA. Considerando-se que em todos os rebanhos caprinos avaliados pelo menos um animal era positivo ou suspeito de infecção por SRLV pelo teste de AGID, provavelmente outros animais do mesmo rebanho também estivessem infectados. Entretanto, indivíduos que apresentem títulos baixos de anticorpos para os antígenos gp135 e p28 de SRLV podem ser diagnosticados como negativos ao teste de AGID, assim como aqueles que apresentam anticorpos para outros antígenos virais não detectáveis através do teste empregado. Estes animais podem ter sido identificados como positivos pelo teste de IFA desenvolvido, o que também justificaria o maior número de animais diagnosticados por esta técnica. Neste caso, os valores estimados de sensibilidade e especificidade do teste de IFA teriam sido erroneamente descritos em virtude da escolha de um padrão impróprio de validade (Fletcher et al. 1996). Finalizando, resultados obtidos em trabalhos com o HIV evidenciam que a técnica de IFA para diagnóstico sorológico de infecção oferece sensibilidade e especificidade equivalentes ao teste de Western blot, sendo superior a este no que diz respeito a facilidade de realização, rapidez e custo (Gallo et al. 1986, Abraham et al. 1994, Ceballos et al. 1998). Além disto, a IFA tem sido utilizada como teste confirmatório quando as amostras de soro de indivíduos suspeitos de infecção pelo HIV são positivas ao ELISA (Yankey et al. 1989, Buchalter et al. 1999). Portanto, com base nestas observações e com trabalhos de aprimoramento desta técnica de IFA, sugere-se que a mesma seja comparada com um teste mais sensível que o de AGID, como por exemplo o teste de Western blot, estimando-se que a IFA utilizada no diagnóstico de infecção por SRLV tenha um desempenho similar àquela empregada para HIV.

\section{REFERÊNCIAS}

Abraham P., Babu P.G. \& John T.J. 1994. Comparison of the indirect immunofluorescence assay with western blot for the detection of HIV antibody. Indian J. Med. Res. 99:143-148.

Alves, F.S.F. \& Pinheiro, R.R. 1997. Presença de artrite-encefalite caprina a vírus (CAEV) no Estado do Maranhão. In: XXV Congr. Bras. Med. Vet., Gramado, p.278. (Resumo)

Archambault D., East N., Perk K. \& Dahlberg J.E. 1988. Development of an enzyme-linked immunosorbent assay for caprine arthritis-encephalitis virus. J. Clin. Microbiol. 26:971-975.

Assis A.P.M.V. \& Gouveia A.M.G. 1994. Evidência sorológica de lentivírus (Maedi Visna/ Artrite encefalite caprina) em rebanhos nos estados de MG, RJ, BA, CE. In: XXIII Congr. Bras. Med. Vet., Olinda, p. 104. (Resumo)

Buchalter M.S., Schneider E.Z. \& Nottar V.L. 1999. Flow chart evaluation for anti HIV serological test. Revta Inst. Med. Trop., S. Paulo, 41 (Supl. 11): S62.

Castro R.S. 1998. Lentivírus de pequenos ruminantes: ensaios imunoenzimáticos, perfil sorológico e inferências filogenéticas. Tese de Doutorado, Escola de Veterinária - UFMG, Belo Horizonte. 132p.

Cavirani S., Donofrio G., Chiocco D., Foni E., Martelli P., Allegri G., Cabassi C.S., De Iaco B. \& Flammini C.F. 1998. Seroprevalence to bovine immunodeficiency virus and lack of association with leukocyte counts in Italian dairy cattle. Prev. Vet. Med. 37:147-157.
Ceballos A., Devito C., Pampuro S., Gomez Carrillo M., Libonatti O. \& Martinez Peralta L. 1998. Evaluation of indirect immunofluorescence as a supplementary test for the diagnosis of HIV-1 infection. Revta Argent. Microbiol. 30:59-63.

Celer Jr V., Celer V., Némcová H., Zanoni R.G. \& Peterhans E. 1998. Serologic Diagnosis of ovine lentiviruses by whole virus ELISA and AGID test. J. Vet. Med. B 45:183-188.

Concha-Bermejillo A. 1997. Maedi-visna and ovine progressive pneumonia. Vet. Clin. North Am. Food Anim. Pract. 13:13-33.

Crawford T.B., Adams D.S., Cheevers W.P. \& Cork L.C. 1980. Chronic arthritis in goats caused by a retrovirus. Science 207:997-999.

Cunha R. G. \& Nascimento M.C. 1995. Ocorrência de anticorpos para o vírus da artrite-encefalite caprina em soros de caprinos do estado do Rio de Janeiro. Revta Bras. Med. Vet. 17:72-75.

Cutlip R.C., Jackson T.A. \& Laird G.A. 1977. Immunodiffusion test for ovine progressive pneumonia. Am. J. Vet. Res. 33:1081-1084.

Daher M.A., Itiama H.S., Mukai M.S., Carneiro R.S.A. \& Kanashiro C.K. 1999. Perfil do teste de imunofluorescência indireta como exame confirmatório para HIV 1 nos laboratórios do Programa Municipal de DST/AIDS de São Paulo. Revta Inst. Med. Trop., S. Paulo, 41(Supl. 11):S19.

Dawson M., Biront P. \& Houwers D.J. 1982. Comparison of serological tests used in three state veterinary laboratories to identify maedi-visna virus infection. Vet. Rec. 111:432-434.

Dezan C.P. 1996. Levantamento epidemiológico da artrite-encefalite caprina em municípios do Triângulo Mineiro e Alto Paranaiba. Monografia, Escola de Veterinária - UFU, Uberlândia. 67p.

Fiterman I.R. 1988. Constatação de complexo artrite-encefalite em um plantel de caprinos no estado da Bahia. XXI Congr. Bras. Med. Vet., Salvador, p.91. (Resumo)

Fletcher R.H. \& Fletcher S.W.; Wagner, E.H. 1996. Epidemiologia Clínica: elementos essenciais. $3^{\mathfrak{a}}$ edição. Artes Médicas, Porto Alegre.

Gallo R.C. 1986. The first human retrovirus. Scient. American, p. 78-88.

Gallo D., Diggs J.L., Shell G.R., Dailey P.J., Hoffman M.N. \& Riggs J.L. 1986. Comparison of detection of antibody to the acquired immune deficiency syndrome virus by enzyme immunoassay, immunofluorescence, and western blot methods. J. Clin. Microbiol. 23:1049-1051.

Garcia M., Galhardo M., Araujo W.P., D’Angelino J.L., Bastos P.S. \& Rossini A.J. 1992. Caprine arthritis-encephalitis (CAE). Occurrence of positive sera in goats raised in Brazil. Trop. Anim. Health Prod. 24:164.

Gogolewski R.P., Adams D.S., Mcguire T.C., Banks K.L. \& Cheevers W.P. 1985. Antigenic cross-reactivity between caprine arthritis-encephalitis, visna and progressive pneumonia viruses involves all virion-associated proteins and glycoproteins. J. Gen. Virol. 66:1233-1240.

Hanson J., Hydbring E. \& Olsson K. 1996. A long term study of goats naturally infected with caprine arthritis-encephalitis virus. Acta Vet. Scand. 37:3139.

Hötzel I., Bastos E.S., Ravazzolo A.P. \& Moojen V. 1993. Caprine arthritisencephalitis virus: isolation and identification in Rio Grande do Sul, Brazil Braz. J. Med. Biol. Res. 23:1175-1179.

Houwers D.J. \& Schaake J. 1987. An improved ELISA for the detection of antibodies to ovine and caprine lentiviruses, employing monoclonal antibodies in a one-step assay. J. Immunol. Methods 98:151-154.

Knowles D.P. 1997. Laboratory diagnostic tests for retrovirus infections of small ruminants. Vet. Clin. North Am. Food Anim. Pract. 13:1-11.

Knowles D.P., Evermann J.F., Shropshire C., Vanderschalie J., Bradway D., Gezon H.M. \& Cheevers W.P. 1994. Evaluation of agar gel immunodiffusion serology using caprine and ovine lentiviral antigens for detection of antibody to caprine arthritis-encephalitis virus. J. Clin. Microbiol. 32:243245.

Leroux C., Chastang J., Greenland T. \& Mornex J.F. 1997. Genomic heterogeneity of small ruminant lentiviruses: existence of heterogeneous populations in sheep and of the same lentiviral genotypes in sheep and goats. Arch. Virol. 142:1125-1137. 
Mahony J., Rosenthal K., Chernesky M., Castriciano S., Scheid E., Blajchman M. \& Harnish D. 1989. Agreement study between two laboratories of immunofluorescence as a confirmatory test for human immnodeficiency virus type 1 antibody screening. J. Clin. Microbiol. 27:1234-1237.

Marchesin D.M., Moojen V. \& Ravazzolo A.P. 1998. Caracterização molecular parcial do gene gag de amostras do vírus da artrite-encefalite caprina (CAEV) isoladas de animais naturalmente infectados no Rio Grande do Sul, Brasil. Pesq. Vet. Bras. 18:119-126.

Melo A.C.M. \& Franke C.R. 1997. Soroprevalência da infecção pelo vírus da artrite-encefalite caprina (CAEV) no rebanho de caprinos leiteiros da região da Grande Fortaleza, Ceará, Brasil. Ciência Rural, Santa Maria, 27(1):113117.

Miyazawa T., Ikeda Y., Maeda K., Horimoto T., Tohya Y., Michizuki M., Vu D., Vu G.D., Cu D.X., Ono K., Takahashi E. \& Mikami T. 1998. Seroepidemiological survey of feline retrovirus infections in domestic and leopard cats in northern Vietnam in 1997. J. Vet. Med. Sci. 60: 1273-1275.

Moojen V. 1996. Caracterização de isolados de lentivírus de pequenos ruminantes naturalmente infectados, do Rio Grande do Sul, Brasil. Tese de Doutorado, Fundação Oswaldo Cruz, Rio de Janeiro. 247p.

Moojen V., Soares H.C., Ravazzolo A.P., Dal Pizzol M. \& Gomes M. 1986. Evidência de infecção pelo lentivirus (maedi-visna/artrite-encefalite caprina) em caprinos no Rio Grande do Sul, Brasil. Arq. Fac.Vet. UFRGS 14:77-78.

Office International des Epizooties 1996. Manual of Standards for Diagnostic Tests and Vaccines. World Organisation for Animal Health, p. 369-373.

Pasick J. 1998. Maedi-visna virus and caprine arthritis-encephalitis virus: distinct species or quasispecies and its implications for laboratory diagnosis. Can. J. Vet. Res. 62:241-244.

Perrin G. 1989. Le rétrovirus de l'arthrite encéphalite caprine. Bull. Acad. Vet. Fr. 62:33-48.

Ravazzolo A.P., Reischak D., Peterhans E. \& Zanoni R. 2001. Phylogenetic analysis of small ruminant lentiviruses from Southern Brazil. Virus Res. 79:117-23.

Remington R.D. \& Schork M.A. 1970. Statistics with applications to the biological and health sciences. Prentice-Hall Inc., Englewood Cliffs, New Jersey. $418 \mathrm{p}$

Rimstad E., East N., Derock E., Higgins J. \& Pedersen N.C. 1994. Detection of antibodies to caprine arthritis-encephalitis virus using recombinant gag proteins. Arch. Virol. 134:345-356.

Rosati S., Kwang J., Tolari F. \& Keen J. 1994. A comparison of whole virus and recombinant transmembrane ELISA and immunodiffusion for detection of ovine lentivirus antibodies in Italian sheep flocks. Vet. Res. Commun. 18:7380 .

Rosati S., Pittau M., Tolari F., Erre G. \& Kwang J. 1995. Genetic and antigenic characterization of CAEV (caprine arthritis-encephalitis virus) recombinant transmembrane protein. Vet. Microbiol. 45:363-370.

Rowe J.D. \& East N.E. 1997. Risk factors for transmission and methods for control of caprine arthritis-encephalitis virus infection. Vet. Clin. North Am. Food Anim. Pract. 13:35-53.

Saraiva Neto A.O., Castro R.S., Birgel E.H. \& Nascimento S.A. 1995. Estudo soro-epidemiológico da artrite-encefalite caprina em Pernambuco. Pesq. Vet. Bras. 15:121-124.

Sell B.E., Pilati C., Rech R.R., Neves D.S. \& Reischak D. 2001. Prevalência de anticorpos para o vírus da artrite-encefalite caprina em caprinos no Estado de Santa Catarina, Brasil. (Submetido à Ciência Rural)

Souza G.J.G. \& Alves F.S.F. 1999. Inquérito sorológico preliminar sobre a artrite encefalite caprina no Estado da Paraíba. XIV Congr. Est. Med. Vet., p. 221. (Resumo)

Yankey R.J., Keiser J.F., Him J.J. \& Wilkinson D.S. 1989. Evaluation of two confirmatory assays, western blot and indirect fluorescence, for the detection of human immunodeficiency virus (HIV-1) antibodies. Diagn. Clin. Testing. 27:48-50.

Zanoni R.G. 1998. Phylogenetic analysis of small ruminant lentiviruses. J. Gen. Virol. 79:1951-1961.

Zapiola I., Alvarez A., Bouzas M.B. \& Muchinik G.R. 1995. Manual de Metodologias de Laboratorio para el Diagnostico de los Retrovirus Humanos. Ed. Sociedad Argentina de Virología, Buenos Aires. 125 p. 